\title{
Influence of the new tender law on construction project bid prices and durations in Kuwait
}

\author{
Ruqaya Al-Sabah and Fatema Abdulrahim \\ Department of Civil and Environmental Engineering, Kuwait University, Kuwait. \\ Corresponding Author: ruqaya.alsabah@eng.ku.edu.kw
}

Submitted: 05/12/2019

Revised: $\quad 09 / 11 / 2020$

Accepted: $14 / 11 / 2020$

\begin{abstract}
The public construction industry is a complex industry that mandates many restrictions, consists of different prolonged phases, and involves various approvals, a great number of authorities, and party associations. The tender stage is crucial in any construction project; it sets the basis of the second party selection to a contract, which is essential for the success of the project. The State of Kuwait issued The New Tender Law (No. 49 of 2016) aligning with the rapid development of laws and regulations. The New Tender Law has introduced twenty modifications, which were included in a survey distributed to a number of participants with experience in the public construction industry in Kuwait. Ninety-three completed surveys were gathered and included in the research's analysis. Box plot and weighted average, along with the standard deviation, were used to sort the twenty tender law modifications according to their influence on bid price and overall project duration. Encouragement of foreign investment, changing contractor classifications, lengthy award processes, and prequalification and the possibility of rebidding are common tender law modifications that have significant impacts on both attributes.
\end{abstract}

Keywords: Construction Industry; Tendering; Construction Law.

\section{INTRODUCTION}

The construction industry represents one of the largest and most influential industries in the world and plays a major role on the global economy. According to the Global Construction Outlook to 2022, Quarter 32018 Update, the global construction industry is expected to rise by the year 2022 to reach KD 3.92 trillion ( $\$ 12.9$ tr.), expanding by an average of 3.6\% per year from 2018 until then, with the Middle East region leading the growth (GlobalData, 2018). The Middle East region as a whole will be the fastest growing region, with an annual average growth of $6.4 \%$. On the other hand, the Gulf Cooperation Council (GCC), a political and economic alliance of six Middle Eastern countries, including the state of Kuwait, formed to achieve unity among its members based on their common objectives and their similar political and cultural identities. The GCC countries have a great influence on the Middle East economy; however, the drop in oil prices has resulted in greatly reducing government revenues in recent years, but oil prices are expected to see a return in growth. Therefore, large-scale investment in infrastructure projects, mostly related to transport, will be a key driving force behind the construction growth in the GCC.

In line with the GCC's vision to enhance their countries' economies and develop their various industries, the state of Kuwait launched its 2035 vision, New Kuwait, as a government-organized plan to transform Kuwait into a regional financial, commercial, and cultural hub in the GCC, where the construction industry plays a major role in the development and growth of the small GCC country and in fulfilling Kuwait's 2035 vision. Kuwait's construction industry covers construction projects in various sectors, such as residential, industrial, and infrastructure construction. The support of Kuwait's government for construction provides many opportunities for development in the country. 
The construction industry in Kuwait is currently booming, with projects valued at KD150.2 billion (\$494.1b.), all at various stages of development, with KD42.8 billion (\$140.9b.) of projects under construction and KD102.7 billion (\$337.7b.) of upcoming projects (Ankit Ojha, 2019). The construction industry appears to be growing and expanding, with the majority of government funding focused on infrastructure, utilities, and housing.

In 2016, a New Tender Law was established to create a public agency named the Central Agency for Public Tenders (CAPT), to take the role of Public Tenders in the State of Kuwait. Presently, the CAPT is responsible for holding tenders to select both the contractor and the designer in public sector projects. In addition, the CAPT is responsible for undertaking the procedures concerned with the public procurement process, starting with its planning, and up to the completion of the contract. The CAPT plays a major role in the tender regulation in Kuwait by enforcing the tender law on all projects related to the public sector. The New Tender Law is a step toward fulfilling Kuwait's 2035 vision.

The modernization of Kuwait's laws and regulations has been part of the 2035 vision. By upgrading Kuwait's laws and regulations and by increasing the flexibility to welcome foreign investors, such changes will lead to a smoothing of the process of doing business in Kuwait (Sha et. al, 2008). Thus, 2016 has been a remarkable year for Kuwait, as it is a year that has brought a raft of regulatory changes in a bid to harmonize commercial objectives with a local and international status. Therefore, this progressive trend has been sustained with the introduction of the New Tender Law.

The New Tender Law includes key provisions that distinguish it from the previous tender law. The aim behind this research is to first study both the New and Previous Tender Laws to address major differences between them. Due to significant changes that were introduced by the New Tender Law, notable impacts on any project's performance are expected. Therefore, the paper showcases how the addressed modifications influence the overall project duration and project's bid price. Finally, both impact measures will be studied from the contractor's and the client's points of view.

\section{LITERATURE REVIEW}

Construction projects worldwide use different processes and utilize diverse delivery stages from start to finish. The tendering phase, for instance, is a crucial step in the success of a project, and the evaluation of bids is a difficult task in determining the most qualified bidder.

Most construction projects' tender stages start by advertising the tender. All projects presented in a public competition should be announced in newspapers, on official websites, or via other mediums. The presented project must give applicants sufficient time to study the tender requirements. Generally, the specific requirements for prequalification for government tenders vary between government agencies and from project to project. Rabia Asif and Sabahat Nisar (2016) studied the tender advertisement cost. The study first analyzed whether the current tender advertisement is cost effective. A survey was performed to determine which advertising mediums are more cost effective for distributing information about tenders. It was concluded that the use of information and communication technologies (ICT) has a great impact on cost effectiveness.

During the tender phase, bidders usually have a limited time to price and submit their final bids. This is due to subcontractors taking more time than expected to return their quotes to the main bidder, which may lead to bidders submitting an inaccurate bid price. Laryea and Lubbock (2014) studied the influence of the allowable time for subcontractors to submit a price to main contractors during the tendering pricing process in the United Kingdom. A survey was conducted, and the survey results, which involved 94 subcontractors, indicated that the time allowed for bidding is insufficient compared to the scale of the work required. Thus, it will affect the accuracy of prices, especially if the quality of the contract documents is not high. This time constraint will have a negative impact on the estimated cost of the work. The results also indicated that the largest barrier to having an effective tendering price is the allowable time for pricing.

Once contractors submit their final bids, evaluating both the financial and technical aspects of the bids may be time-consuming. Therefore, the European Parliament is promoting the implementation of new tendering strategies and innovative approaches, such as building information modeling (BIM) and other similar electronic modeling tools, in 
public works contracts and design contests (The European Parliament, 2014). The information available during the bidding phase is often inadequately transferred and is usually misinterpreted since the data are mostly paper-based, and the drawings are often in 2D. In addition, discrepancies between engineering design drawings are present, and miscalculations of quantities generally result in false bidding prices during the tendering phase, followed by claims, disputes, and back-charges when they are discovered during the construction phase, which will negatively affect the project's progress.

Risk identification is the process of determining risks that could potentially prevent a project from achieving its objectives. Therefore, risk identification is extremely important during the tendering stage. Bajaj et al. (1997) address the process of risk identification at the tendering and estimating stage. This work classified and evaluated the process of risk identification for construction contractors in Australia. The data in the paper were collected from December 1994 to January 1995 through a survey that was distributed to nineteen construction contractors. The results of the survey were analyzed using a frequency distribution. The obtained results show that top-down techniques were the most commonly used methods for risk identification by construction contractors.

In addition, Cheaitou et al. (2018) developed a framework for the decision-making process. The study supports the public sector in suitable construction contractor selection. The paper mentions that risk exposure during the tendering process is usually very high and that the success of the construction project is strongly related to managing the risk appropriately. Therefore, the selection of the contractor should be based on a set of criteria, such as the technical capability, financial stability, and safety. Such criteria, in addition to the cost, should be taken into consideration to avoid problems that may arise after signing the contract. In addition, the study uses a mixture of multicriteria decisionmaking tools to assist in selecting the most appropriate contractor. Each country has its own set of criteria when selecting the contractor, and each country has its own tendering procedure and laws that it follows.

On the other hand, GCC countries have many similarities; however, the tendering phases and laws differ from one country to another. For instance, in the Kingdom of Saudi Arabia, the tender act is referred to as "the system of securing the purchases of the government and the implementation of its project and businesses" (Ministry of Foreign Affairs, KSA, 2017). The tendering procedure is extremely competitive and is governed by the Government Tender and Procurement Law (GTPL) and its regulations. According to the GTPL, the initial bond percentage is $1 \%-2 \%$, whereas the final bond is $5 \%$ of the contract's price. These percentages are lower than Kuwait's law percentages, in which is at least $1-5 \%$ of the bid price is assigned for the initial bond, and $10 \%$ of the contract's price is assigned for the final bond. By increasing the percentage of bonds, the contractor will be more liable to perform and complete the contract. However, it might decrease the participation rate of contractors.

The Kingdom of Bahrain established a tender board in 2002. The tender board works to promote efficient government procurement practices and systems through a strict regulatory mechanism designed to ensure the utmost fairness and equal opportunity. The tender board has set tendering laws for all public procurement practices in the Kingdom. There are noticeable differences in the tendering laws of the Kingdom of Bahrain from Kuwait's tendering laws. In Bahrain's tendering laws, it is stated that the board of Bahrain shall prepare an annual report of its activities that contains performance indicators, and this report shall be published in the official gazette within 3 months of the end of the financial year. A public tender shall be advertised in one or two local daily newspapers or as the Board deems appropriate. For the tenders whose value exceeds BD1 million $(\$ 2.65 \mathrm{~m}$.), the advertisement shall also be published in the official gazette. Moreover, a contract in Bahrain shall be effective immediately upon the issuance of an award decision to the successful bidder, and the contract shall be signed between the buyer and the bidder who has been awarded the contract within a maximum of 30 days from the date of issuing the award decision. A supplier or contractor may file a complaint with the Board in some cases, and the decision of the Board can be challenged before the competent court within 30 days from the date of informing the contractor. The contractor may also file a challenge with the law courts with respect to any final action or a decision adopted within 60 days from the date of becoming aware thereof. Finally, Bahrain's tendering law includes an article that prohibits contractors from engaging in any practice leading to a monopoly. 
In the United Arab Emirates (UAE), government entities follow a fair and transparent system for tendering and awarding contracts. All invitations to bid are made public and are accompanied by a clear set of guidelines that bidders must follow. In the UAE, public and private sectors create many investment opportunities, such as tenders and auctions, which are advertised through many newspapers and websites. Various ministries in the UAE and federal agencies regularly submit their tenders and practices to the Ministry of Finance's "Register of Suppliers". This means that all federal ministries and suppliers can access and participate in these tenders and practices by registering in the supplier register and subscribing to this system. The UAE has simplified the submission of bids by developing an application for bidding and by accepting online submissions (Ministry of Finance, UAE, 2018). Such practices for submitting a bid differ from those in Kuwait.

There are many similarities and differences in the tendering laws and procedures of Kuwait and other GCC countries. Al-Fares (2000) proposed a thesis to evaluate the economic role of central tendering with fivefold aims, which are as follows: 1. to control the major areas of government spending on services and development projects; 2. to reduce the expenses of government departments when buying from private suppliers and to ensure the highest quality of provision; 3 . to organize, standardize, and unite all tendering procedures for all government departments; 4 . to avoid a breach of trust between government departments and employees; and 5. to treat all contractors who tender with fairness, to avoid favoritism throughout the tender procedures, and to highlight the organizational nature of the slow responding and highly bureaucratic structure. The evaluation showed that simplification of the procedures and acceleration of the process would provide many more benefits (Al-Fares, 2000). From the research, it was found that the fivefold aims are to recognize the worthiness of the tendering committee. It is shown that the aims are all being met to a greater or lesser degree, but it is revealed that a simplification of the procedures and a speeding up of the process would provide many more benefits.

In 2016, the CAPT took over public tenders in Kuwait and issued "The New Tender Law". There were no research papers found that compared Law No. 49 of 2016 issued for the CAPT with Law No. 37 of 1964, which was issued for the Central Tenders Committee (CTC). Therefore, this research was conducted to display and identify the similarities and differences between the laws and to study the effect the new law will have on the tendering stage through various points of view.

\section{MODIFICATIONS OF THE NEW TENDER LAW}

In the 1960s, a rapid development and growth in the construction industry occurred, which resulted in the need for a law to regulate the contracts between public authorities, construction companies, and material suppliers. Therefore, in 1964, his highness, the late Sheikh Jaber Al Ahmed Al Sabah, issued the public tender law, which contains 66 articles that organize and regulate tender practices in the state of Kuwait. As the country developed, the construction industry grew, and as time progressed, the law created in the 1960s no longer fulfilled and covered all the topics and issues the construction industry was facing in the 21 st century. Thus, a new updated law was required; therefore, in 2016, Law No. 49 of 2016 (the New Tender Law) was established to replace Law No. 37 of 1964. The New Tender Law includes key provisions that distinguish it from the previous tender law.

Prior to the CAPT, any public authority could issue their own contracts through the CTC, as the CTC was established to assist the public sector in the State of Kuwait in making their own decisions regarding projects that are related to their specific authority. With the establishment of the New Tender Law, the CAPT has taken over the tender practice and public sector projects in Kuwait. The New Tender Law mentions that public authorities may not import items or assign contractors, nor may they issue contracts to purchase or rent things or provide services; such tasks may be undertaken only through the CAPT. In addition, any task performed through the CAPT must be approved by the board of directors. As provisioned by Article 5 in the New Tender Law, the board of directors consists of twelve members in total. Seven members are nominated and approved through the council of ministries, and among them, a chair and vice chair will be appointed. The remaining five members are representatives from various public authorities. Therefore, the CAPT is responsible for issuing all contracts related to public sector 
projects in Kuwait, with the exception of Article 17, which declares that the relevant public authority may issue a contract without permission from the CAPT if the value of the contract does not exceed KD 75,000.

The introduction of the New Tender Law aims to make the procurement process easier; therefore, electronic means, such as the CAPT website, are used to ease and improve the method of communication between all related parties. Thus, all documents, notifications, decisions, and announcements are easily accessible. Such electronic means can also be used to advertise for tenders and to post prequalification requests. According to the New Tender Law, the process for the proposal submission and prequalification requirements should be incorporated in the tender documents. According to Article 38, the announcement of the invitation for tender or for submitting bids or prequalification requests should be published in the Official Gazette, as well as on the CAPT website, no later than thirty days from the deadline.

The prequalification of bidders' requirements can be performed by the public authority requesting the tender or according to the contractors' categories set by the Law. The CAPT classifies contractors for public tenders into four categories according to their financial and technical capabilities. The previous tender law classified category 1 contractors for only projects worth more than KD1 million. Due to the inflation of prices in the previous years, the old classification led to most of the contracting companies falling under one category, which caused the majority of public tenders being awarded to unqualified bidders. Therefore, the New Tender Law has changed the classification categories to ensure that a qualified tenderer is awarded to the project. The new law classifies contractors as follows: category 4 contractors for projects less than KD 2 million; category 3 contractors for projects from KD 1-10 million; category 2 contractors for projects worth KD 5-100 million; and category 1 contractors for projects worth more than KD 10 million.

The New Law gives contractors sufficient rights and guarantees contractors absolute transparency by establishing a grievance committee. The committee resolves any issues during the tender stage, considers grievances of contractors, and assures prevention of conflicts of interest; therefore, participants of tenders should declare if they are somehow related to a member of the board of directors or the authority requesting the tender. Thus, this will lead to requiring the member of the board, the staff of the agency, and the staff of the relevant authorities or any person who participates in the work of tenders to refrain from participating in all procedures.

Kuwait's goal, through the New Tender Law, is to attract foreign investors and to be able to expand into the international commercial market by easing regulations and providing an investor-friendly economy. Prior to the New Tender Law, foreign contractors were unable to bid on public tenders without having a local agent or representative. With the New Law, foreign firms are now able to enter government tenders, which used to be exclusive to Kuwaiti firms. The presence of the Kuwaiti firms is still maintained in the public tender marketplace, as the New Law obliges foreign contractors to meet no less than $30 \%$ of its contractual requirements from the local market or from local suppliers that are registered with the CAPT. Therefore, the New Tender Law provides support for the national product and local firms, especially for small and medium sized enterprises. In addition, foreign firms must award at least $30 \%$ of their work load to local firms, as this gives local entities the opportunity to learn new skills and gain knowledge from foreign contractors with distinguished experiences. As opposed to the previous law, Article 71 of the New Tender Law mentions regulation of subcontractors and states that subcontractors shall be eligible for the implementation of the obligations of the original contractor under the contract with the public authority.

In addition, the previous tender law did not recognize nor regulate the technical evaluation of the various project tenders. According to Article 39 in the law, the criteria for selecting, evaluating, and determining the lowest bidder should be mentioned in the tender documents. In the New Tender Law, a point system is used by the CAPT to allocate project work of a technical nature to a selected bidder based upon the successful attainment against a specified pointbased criterion. According to the regulations in the New Tender Law, when a tender is awarded, the contract should be signed in a period not exceeding three months from the date of the expiration of the period of bidding. Once the successful bidder is notified, the contractor should submit the performance bond within 30 days. The new law determines the value of the performance bond, which is equal to at least $10 \%$ of the total contract value. 
Once the project is appointed, the contractor has the opportunity to fix the prices that were mentioned in the offer according to a specific equation mentioned in the contract documents in case of an escalation of material prices. In the case of variation orders, unlike the previous tender law, Article 74 mentions that the relevant authority shall not be allowed to issue changes of the contracts that equal $\pm 5 \%$ of the total value of the contract without the consent of the CAPT. Furthermore, a new criterion for potential bidders is developed. According to the New Tender Law, companies that are not able to execute a contract or did not execute a contract according to the requirements will not be allowed to participate in new tenders until the issue of dispute is resolved. This addition to the new law will help protect public money from incompetent contractors. Finally, the new law states that, in the case of a tender having only one bidder, retendering can be conducted with the approval of two-thirds of the present members.

Overall, the New Tender Law shows a total of 20 modifications compared to the previous law; a summary of all the identified modifications is listed in Table 1.

Table 1. New Tender Law Modifications.

\begin{tabular}{|c|c|}
\hline No. & New Tender Law Modifications \\
\hline 1 & Abolition of absolute discretion \\
\hline 2 & Following the publicity principle in the tendering and decision-making method \\
\hline 3 & Cancellation of the condition requiring local agents and encouraging foreign investors \\
\hline 4 & Supporting small and medium-sized enterprises \\
\hline 5 & Supporting national products and local contractors \\
\hline 6 & Subcontracting regulation \\
\hline 7 & Conflict of interest prevention \\
\hline 8 & Changing contractors classifications \\
\hline 9 & $\begin{array}{l}\text { Development of a mechanism for the study of technical proposals ( } 30-60 \text { days maximum) and } \\
\text { financial proposals (one or two phases) }\end{array}$ \\
\hline 10 & Selection and evaluation standardization \\
\hline 11 & Direct contracting authorization (for amounts not exceeding KD 75,000 annually for the same item) \\
\hline 12 & Agency permission in issuing variation orders (if they exceed $5 \%$ of the contract price) \\
\hline 13 & Adjusting materials prices according to a special formula \\
\hline 14 & $\begin{array}{l}\text { Tenders subject to prequalification (allowing the opportunity to list the names of companies that are } \\
\text { not included in the prequalification list) }\end{array}$ \\
\hline 15 & Using information and communication technology \\
\hline 16 & $\begin{array}{l}\text { Rebidding possibility (with the approval of two-thirds of the members of the Board of Directors of } \\
\text { the Authority) }\end{array}$ \\
\hline 17 & Sole bid accepting possibility \\
\hline 18 & Increasing the number of members of the Board of Directors \\
\hline 19 & Performance bond value determination (not less than $10 \%$ of the total contract value) \\
\hline 20 & Lengthy award Process \\
\hline
\end{tabular}




\section{METHODOLOGY}

The research methodology consists of three phases: (1) survey formation, (2) data collection, and (3) data analysis. The survey was designed to collect construction participants' perspectives, who are or were engaged in public projects in the State of Kuwait, with regard to the modifications implemented in the New Tender Law. The survey's participants were asked to assess the influence of the twenty new law modifications (presented in Table 1) on both the bid price and the project duration, as defined in Table 2.

Table 2. Bid Price and Project Duration Influence Definitions.

\begin{tabular}{|l|l|}
\hline Attributes & \multicolumn{1}{c|}{ Definitions } \\
\hline Influence on Bid price & The law modification's influence on bid price provided by tenderer. \\
\hline Influence on Project duration & $\begin{array}{l}\text { The law modification's influence on project's lifecycle schedule and duration } \\
\text { including the tender, construction and maintenance phases. }\end{array}$ \\
\hline
\end{tabular}

Based on an intensive examination of both the new and the old tender laws, the twenty identified modifications were discovered and incorporated into the survey. The main objective of the survey is to evaluate the influence of the twenty modifications on project duration and bid price.

The survey participants were asked to score the twenty law modifications with regard to two attributes, i.e., bid price and project duration, on a five point Likert-type response scale with $1=$ no impact, $2=$ low impact, $3=$ medium impact, 4=strong impact, and 5=very strong impact.

The research data collection was performed to gather the perspectives of three different groups from the research populations, consisting of owners, contractors, and mixed identity participants. The first group targeted owners and owners' representatives only, where many public sector organizations, such as ministries, authorities, and departments, were contacted to capture their perspectives on both bid price and project duration. The research team ensured that the participants were familiar with the modifications introduced by the new tender law and the tender process in the public sector in Kuwait. Additionally, the surveys were forwarded to contractors and subcontractors with different classifications who formerly submitted bids to various public construction projects and were familiar with the public construction cycle. The survey was also completed by mixed identity participants where their responsibilities in the project were disclosed from the research team. A total of ninety-two (92) completed surveys were gathered from the three groups in total. The majority of the survey participants were from owners and owner representatives, representing $38 \%$ (i.e., 35 out of 92), contractors and subcontractors constitute $30 \%$ (i.e., 28 out of 92), and, lastly, the mixed identities participants represent $32 \%$ (i.e., 29 out of 92) of the sample size. The characteristics of the research sample are illustrated in Figure 1.

The owners' and contractors' perspectives were collected separately to clearly identify their approach concerning the new law modifications. Nevertheless, the mixed group survey participants' viewpoints were cross-examined to perspicuously distinguish the construction participants' opinions while holding their identities constant. Finally, the analysis was performed for all three groups independently; and it was also executed for the overall ninety-two (92) cases.

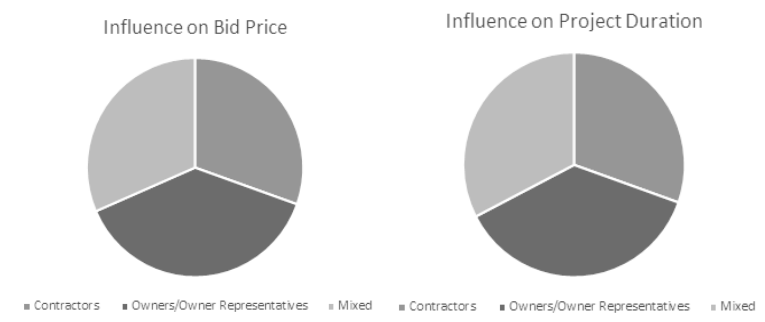

Figure 1. Survey Respondents' Characteristics. 
The weighted average, standard deviation, and box plot were computed for the bid price and project duration from the contractors, owners, mixed, and all cases. The weighted average is a score that is intensively used in the construction industry to rank different observations (Chan \& Kumaraswamy, 1997; Aibinu \& Jagboro, 2002). The weighted average for each law modification for the four groups was computed for both bid price and duration attributes and ranked accordingly. Standard deviation is a measure of how disperse a data set is (Raes et al., 2011; Al-Momani, 2000). Additionally, the standard deviation was calculated for each law modification, to be used as a secondary measure in case the weighted average cannot represent the actual position of the law modification. On the other hand, a box plot is a graphical representation of the observation spread and provides descriptive statistics that are essential to the orientation of the observation distribution. The median stipulates a good measure of the average value when the data include exceptionally high or low values because these have little influence on the outcome. Box plots were used in many construction-related studies, to visually describe a data set, and were used to compare different distributions (Gebken \& Gibson, 2006).

Statistical Package for the Social Sciences (SPSS), a software package used for the analysis of statistical data, was utilized in this study to compute the weighted average and standard deviation and produce the box plots for four participant groups on both price and time attributes.

The numerical scores assigned by respondents in the survey were transformed to weighted average and standard deviation using Eq. (1) and Eq. (2).

$$
\begin{aligned}
& \text { Weighted Average }(\underline{x})=\sum_{\mathrm{i}=1}^{5} \frac{\mathrm{Wixi}}{\mathrm{N}} \\
& \text { Standard Deviation }(\sigma)=\sqrt{\frac{\sum_{\mathrm{i}=1}^{5}\left(\mathrm{x}_{\mathrm{i}}-\underline{\mathrm{x}}\right)^{2}}{\mathrm{~N}-1}}
\end{aligned}
$$

where the variable definitions are as follows:

$W_{\mathrm{i}}=$ Weight allocated to the ith response, i.e., 1, 2, 3, 4, or 5. Accordingly, $W_{1}=1$ is assigned for no impact, $W_{2}=2$ is assigned for low impact, $W_{3}=3$ is assigned for medium impact, $W_{4}=4$ is assigned for strong impact, and $W_{5}=5$ is assigned for very strong impact.

$X_{\mathrm{i}}=$ Number of respondents corresponding to the weight category for a particular influence, including the bid price and project life-cycle duration.

$N=$ The total number of respondents in each group.

$I=$ Response category index $=1,2,3,4$ and 5.

$\underline{x}=$ The mean weight category for a particular influence, including bid price and project life-cycle duration.

\section{RESULTS}

The weighted average, standard deviations, and box plots for the twenty modifications for each group were obtained from both attributes and ranked in descending order. Table 3 summarizes the top tender law modifications. on the other hand, four different box plots were produced for the twenty law variations for the influence on bid cost and project duration as presented in Figures 2 and 3. These box plots will allow the research team to better examine each law difference distribution and determine the top influential difference from both bid price and project duration. 
Table 3. Top Tender Law Modifications.

\begin{tabular}{|c|c|c|c|c|c|c|c|c|c|c|c|}
\hline \multicolumn{12}{|c|}{ Influence on Bid Price } \\
\hline \multirow{5}{*}{ 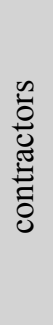 } & Difference & Mean & \multirow{5}{*}{ 峁 } & Difference & Mean & \multirow{5}{*}{$\stackrel{\overrightarrow{0}}{\stackrel{x}{\Sigma}}$} & Difference & Mean & \multirow{5}{*}{$\bar{z}$} & Difference & Mean \\
\hline & D8 & 4.25 & & D3 & 4.54 & & D3 & 4 & & D3 & 4.13 \\
\hline & D17 & 4.25 & & D17 & 4.03 & & D5 & 3.97 & & D8 & 3.89 \\
\hline & D16 & 4.14 & & D6 & 3.94 & & D2 & 3.76 & & D17 & 3.86 \\
\hline & D14 & 3.96 & & D2 & 3.83 & & D8 & 3.69 & & D16 & 3.68 \\
\hline \multicolumn{12}{|c|}{ Influence on Project Duration } \\
\hline \multirow{5}{*}{ 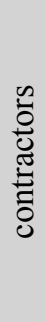 } & Difference & Mean & \multirow{5}{*}{$\overbrace{0}^{\infty}$} & Difference & Mean & \multirow{5}{*}{$\stackrel{\vec{\circlearrowright}}{\stackrel{凶}{\Sigma}}$} & Difference & Mean & \multirow{5}{*}{$\bar{Z}$} & Difference & Mean \\
\hline & D20 & 3.54 & & D3 & 4.29 & & D12 & 4.47 & & D12 & 4.03 \\
\hline & D14 & 3.54 & & D11 & 4.2 & & D15 & 4.1 & & D11 & 3.75 \\
\hline & D16 & 3.5 & & D12 & 4.09 & & D20 & 4.03 & & D20 & 3.73 \\
\hline & D12 & 3.5 & & D6 & 3.83 & & D9 & 3.93 & & D15 & 3.7 \\
\hline
\end{tabular}
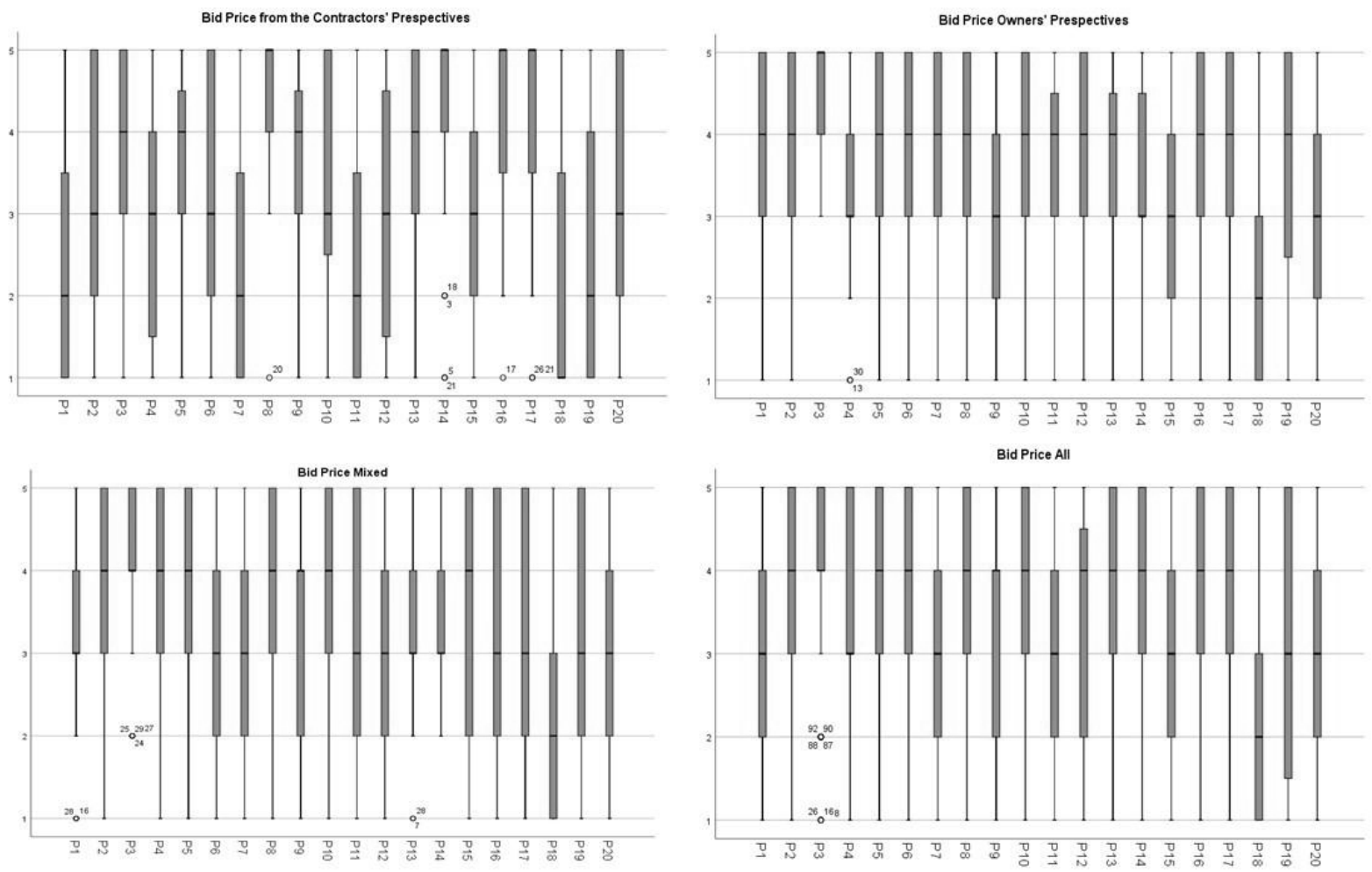

Figure 2. Box Plots for Influence on Bid Price. 

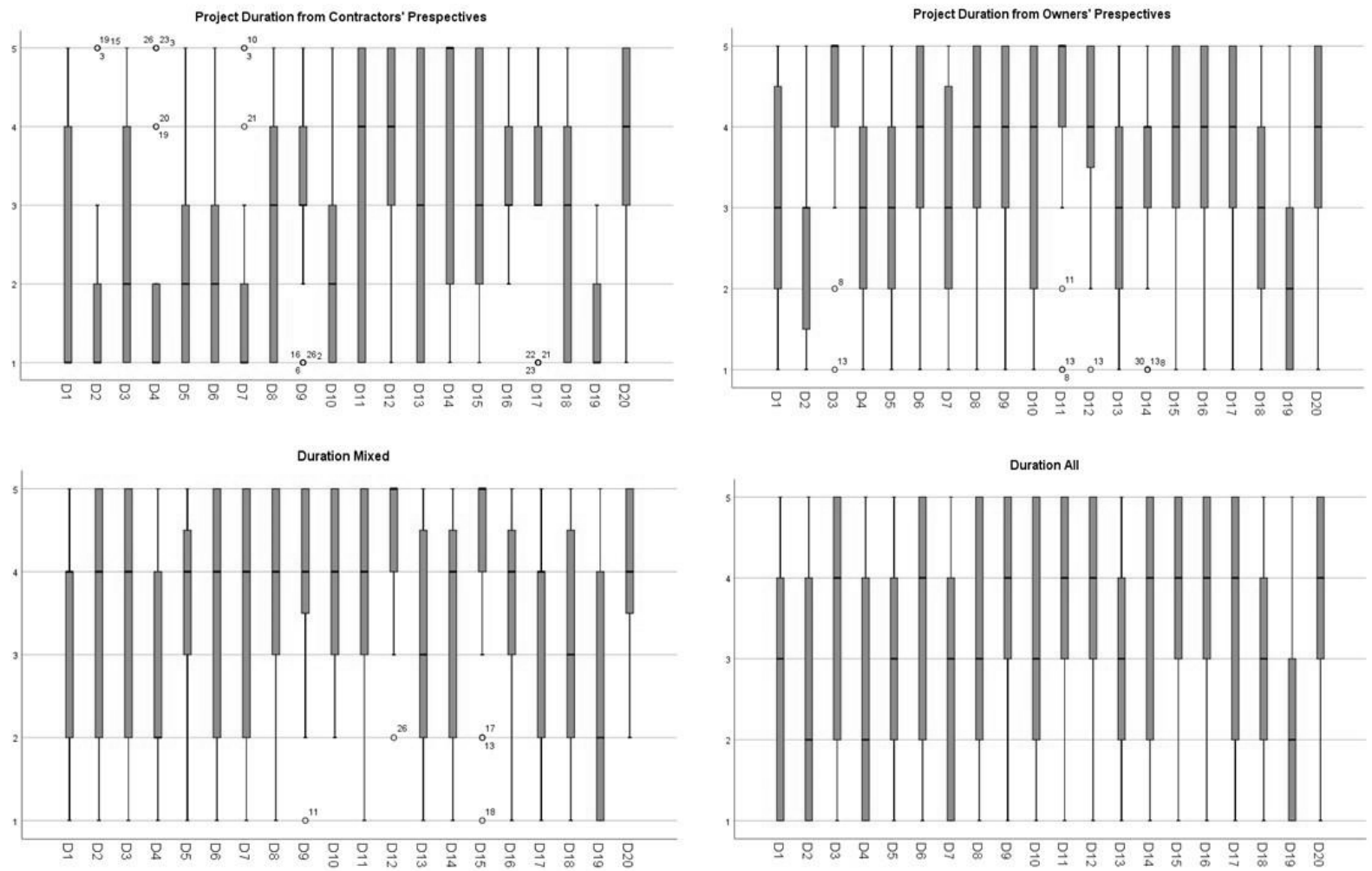

Figure 3. Box Plots for Influence on Project Duration.

The research team examined the outcomes of the research analyses and recognized the following.

\section{Influence on Bid Price}

The present study has focused on analyzing the influence of the twenty differences on bid cost from the perspectives of four distinct groups, which are as follows:

\section{a. Contractors}

By examining the box plot shown in the top left corner of Figure 2, for the influence on the bid price from the contractors' perspective, it has been noticed that the top law differences, which have skewed distributions toward the higher end of the ranking range, with a median of almost 5, are as follows: D8, D14, D16, and D17. On the other hand, when considering the top differences with respect to the weighted average presented in Table 3, the research team has concluded that D8, D17, D16, and D14 were the top influential differences.

The top differences were both D8 and D17, with a weighted average of $(\underline{x}=4.25)$. The change in the contractors' classifications was dramatically modified in the New Tender Law and is presented in Table 4. This change has direct influence on bid price, as contractors with higher classification are more qualified and experienced and will provide an accurate bid price with minimal errors. 
Table 4. Contractors' Classifications.

\begin{tabular}{|l|l|l|}
\hline Classification & \multicolumn{1}{|c|}{ CTC limitations } & \multicolumn{1}{c|}{ CAPT limitations } \\
\hline Class A & Estimate $>1 \mathrm{M}$ and $\sum 5 \mathrm{M}$ & Estimate $>10 \mathrm{M}$ \\
\hline Class B & Estimate $\prec 1 \mathrm{M}$ and $\sum 1 \mathrm{M}$ & $100 \mathrm{M} \geq$ Estimate $>5 \mathrm{M}$ \\
\hline Class C & $\sum 500 \mathrm{~K}$ & $10 \mathrm{M} \geq$ Estimate $>1 \mathrm{M}$ \\
\hline Class D & local contractors and $\sum 250 \mathrm{~K}$ & $2 \mathrm{M} \geq$ Estimate \\
\hline
\end{tabular}

M: Million, K: Thousand, values are in Kuwaiti Dinars.

However, accepting a sole bid has different mechanisms in the old and the new tender laws. The old tender law emphasized that the foremost action of having a sole bid is to retender; however, in the case of acceleration, a secondary action would be to accept the sole bid with the condition of obtaining approval from $2 / 3$ of the CTC members. However, the primary action in the new law was to accept the sole bid if it meets the tender conditions. A retendering option is always available when it conforms to the public interest; however, approval from $2 / 3$ of the CAPT members should be obtained.

Regarding the sole bid acceptance strategy introduced in the new tender law, which has a direct influence on the bid price, submitting one bid will lead to tender predominance and signing the contract without having the opportunity to ensure its appropriate bid cost.

\section{b. Owners/Owner Representatives}

From the box plot illustrated in the top right corner of Figure 2, for the influence on the bid price from the owners' perspective, it was observed that the top law difference about the median is only D3. However, by considering the top difference with respect to the weighted average presented in Table 3, it was noticed that the same difference contributed to the highest weighted average of 4.54 among the entire research's results. As D3 is the top difference for both parameters, it should be given special consideration, as it has a great influence on the bid cost from the owners' perception. The new tender law has made it easier for foreign investors to become involved in the construction industry in Kuwait without requiring a local partner, as was requested by the old tender law. It has introduced new articles that offer many advantages for foreign companies, and it has restricted some projects to foreign companies. For these reasons, allowing foreign investors to become involved in the local construction industry has many advantages, as it will enhance project performance with regard to cost, time, and quality. Foreign firms' involvement can elevate the production capabilities of local participants such as contractors who had been involved in many heavily specialized projects.

\section{c. Mixed Identities}

After examining the mixed identities group bid cost influential parameters, including the box plot presented in Figure 2 and the weighted averages listed in Table 3, it was concluded that the most influential law difference with regard to both parameters was D3, which confirms that, by holding the participants' identity constant, D3 still has the highest impact on bid cost.

\section{d. All Participants (inclusive)}

All participants' perceptions, including contractors, owners, and mixed identities, with regard to bid cost, were comprehensively examined. The box plot provided in Figure 2 and the weighted average presented in Table 3 have been used to determine the top law difference that has the most influence on the bid cost. The investigation has confirmed that D3 has the top influence with regard to the bid cost from both parameters. However, the weighted average has extended the influence of D8 by ranking it second. Therefore, based on the results discussed, it was concluded that the most influential differences with regard to bid cost were D3 and D8. 


\section{Influence on Project Duration}

On the other hand, an analytical approach on the influence of the twenty law variations on the project duration from the perspectives of the four groups emphasized the following:

\section{a. Contractors}

The box plot shown in the top left corner of Figure 3 describes the new law modifications' influence on project duration from the contractors' perspective. It was observed that no certain modifications of the new tender law have significant impact on project duration. However, when addressing the top new law modifications with respect to the weighted averages presented in Table 3, it has been observed that D20, D14, and D16 are the three top influential differences with regard to the project duration from the contractors' perceptions, with weighted averages of 3.54, 3.54, and 3.5 , respectively.

Law No. 49 of 2016 articulated new clauses that clearly define the award process and introduced various additional steps that include complexity and broadcasting the award cycle. First, the new tender law has explicitly divided the bid submission into two parts, including "technical bid", which has to be examined prior to opening the financial bid, and "financial bid", which will be reviewed only for approved technical bids. According to Article 51, the financial bid examination will take place at a stage in the award process where the recommendation of the technical bids has been finalized, which adversely influences the award's total duration. Second, it has been noted that the new tender law has inaugurated regulatory periods, such as a technical bid examination period of 30-60 days (Article 49), an announcement of the price list period of 5 days (Article 52), awaiting the relevant authority's final approval for almost 10 days (Article 63), agency notification of a successful tenderer that could take a period of 7 days (Article 63), and finally, notification of a successful tenderer to provide a performance bond to sign the contract, which can take 10-30 days (Article 65). A total of 62 to 112 days were added to any public contract award process; this addition will extend the award process. A comparison between the new and the old tender law bid award processes is shown in Figure 4.

On the other hand, the prequalification procedure is thoroughly discussed in the new tender law. According to Article 32 , the relevant authority is responsible for prequalifying the designers or/and contractors, and the prequalified entities should submit all requested documentation to the relevant authority so that it can be fully examined. Additionally, the qualified firms list shall be published in the official gazette for a period of 30 days to enable unlisted entities to be included if they fulfill the qualification conditions (Article 38). This can directly impact the project duration, as it may contribute to an additional 30 days before the tender phase can commence.

Finally, the new tender law provides the opportunity to rebid on more than one occasion, such as when submitting a single bid and when the bidder refuses to redistribute the unbalanced bid prices. Therefore, the project duration will be hindered by the retendering process, as it will postpone the project completion until the bid is awarded and the contract is signed.

\section{b. Owners/Owner Representatives}

The box plot shown in the top right corner of Figure 3 illustrates the top modification influences on the project duration from the owners' perspective. It was perceived that D3and D11 in the new tender law have significant effects on the project duration. Additionally, examining the top new law modifications with respect to the weighted average presented in Table 3 revealed that D3 and D11 were the top modifications with respect the project duration, confirming the conclusion of the previous analysis. The two top influential differences with regard to project duration from the owners' perception have weighted averages of 4.29 and 4.2 . 


\section{Bid Award Process}

Law No. 49 of 2016

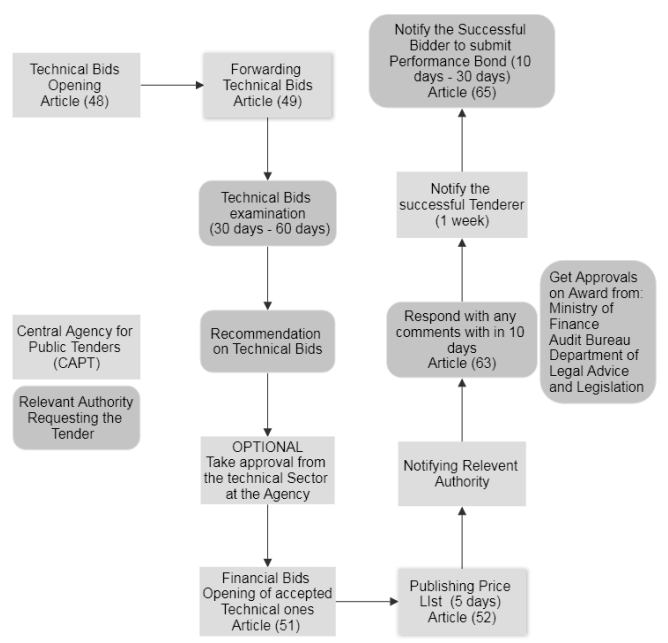

Law No. 37 of 1964

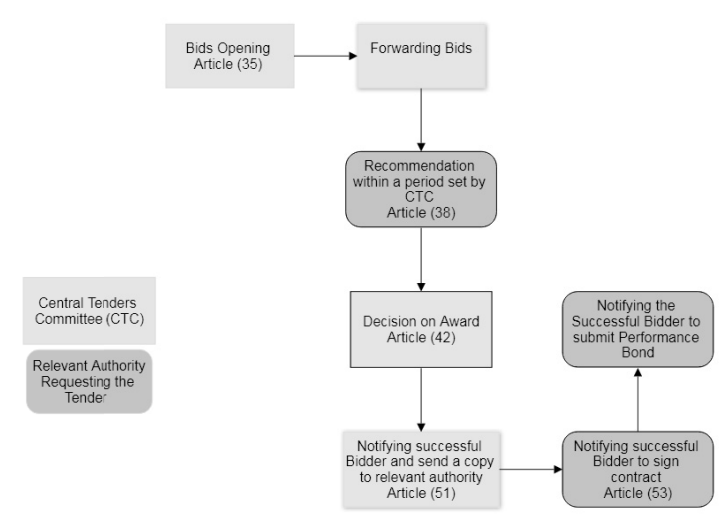

Figure 4. New and Old Tender Law Bid Award Process.

Encouragement of foreign investors in Kuwait's construction industry has been one of the substantial adjustments of the new tender law. It has made it simpler for foreign firms to be involved in construction projects, as it diminishes all the restrictions and setbacks that the firms could encounter from the old tender.

Authorization of direct contracting is a newly introduced strategy, where the relevant authority can directly enter into a contract without having approval from the CAPT. A direct contract can be of a value not greater than KD 75,000, which gives the relevant entity the freedom to engage in contracts without any restrictions. The research team has found that the "authorization of direct contract" was a great modification to the tender law and had a positive impact on project duration.

\section{c. Mixed Identities}

The box plot presented in the bottom left corner of Figure 3 illustrates the impacts of the top variations on project duration from a mixed identities viewpoint. It was discovered that D12 and D15 of the new tender law have crucial consequences on the project duration. Additionally, examining the top new law variations with respect to the weighted average presented in Table 3, it was observed that D12 and D15 were the top modifications with respect to the project duration, with weighted averages of 4.47 and 4.1 , respectively.

The new tender law enhanced the variation orders mechanism, as it gave the public authorities the ability to increase or decrease the contract value by $5 \%$ of the total value of the contract without having consent (Article 74). This enhancement has smoothened the process involving any change, which relieves the agency from being overly bureaucratic in decision making, especially with regard to small changes, and enhanced the project time performance.

Moreover, it was notable that by simplifying the public contract engagement process, as mentioned in (Article 74), has a positive impact on project duration.

Using information and communication technology was one of the substantial changes that had various citations in the new tender law. It was one of the main pillars of the New Kuwait 2035 to stay on top of emerging technology trends, and the new tender law has addressed that change accordingly. The new tender law has promoted the use of 
technology, electronics, and programs in public procurements, documentation, and the means of communication, resulting in improved project performance with regard to duration.

\section{d. All Participants (inclusive)}

The box plot presented in the bottom right corner of Figure 3 illustrates the impacts of the top variations on project duration from all participants' perceptions. It was observed that no single modification has a special influence on project schedule. Additionally, the examination the top new law variations with respect to the weighted average presented in Table 3 revealed that D12 and D11 were the top modifications with respect to project duration, with averages of 4.03 and 3.75, respectively. Both modifications have been thoroughly discussed previously.

\section{Influence on Bid Price and Project Duration}

The research team examined the top law variations with a significant mutual influence on both attributes. It was noted that the owners' group confirmed that D3 was the top law variation with significant influences on both project performance measures. On the other hand, D14 and D16 were the most significant variations from the contractors' perspective for both attributes.

Accordingly, the research team has concluded that a construction participant seeking the involvement in construction bids for projects located in the State of Kuwait or any other countries within the Gulf region, as they have similar regulations, has to intensify their examination of the tender law, as it will profoundly influence their bid price, project duration, or both. The encouragement of foreign investors, changing contractor's classification, lengthy award process, variation orders mechanism, direct contracting authorization, prequalification, and rebidding are the common tender law that has significant impacts on construction project performance. Owners have to confirm that their contracts stipulate these variations and thoroughly discuss them to overcome any adverse consequences. Additionally, governments have to accommodate these modifications in their laws and regulations to mitigate their unfavorable influence on the construction industry. Table 5 summarizes the most influential law variations on both performance attributes.

Table 5. Influential Law Variations Summary.

\begin{tabular}{|l|l|l|l|l|}
\hline Attribute & Contractors & Owners & Mixed & All \\
\hline Cost & D8 & D3 & D3 & D3 \& D8 \\
\hline Duration & D20 & D3 \& D11 & D12 & D12 \& D11 \\
\hline Both & D14 \& D16 & D3 & none & none \\
\hline
\end{tabular}

\section{CONCLUSION}

Construction project procurement is subject to various types of difficulties throughout different project phases. Construction-related constraints can be classified as country-regional or construction-performance issues that would be encountered by any construction participant. Country-regional constraints are mainly imposed by the country's government through its jurisdiction and legal-body and can influence project time or cost indices. Therefore, construction constraints have to be well recognized and allocated to the best contract party who can properly manage and control it. Constraint recognition and allocation are best accomplished at the early stages of any project by drafting contracts with the terms and clauses that best describe each party's rights and obligations in accordance with the country's laws and regulations. Accordingly, jurisdiction laws and regulations should be in line with world development and should be written to last and be flexible to accept any future modifications.

Based on that and with the advancement in the construction industry, professional laws should be rewritten to cover the constraints encountered in each phase discreetly. For instance, law No. 49 of 2016 was issued to emphasize the tender stage and overcome the drawbacks experienced by previous tender law in the State of Kuwait. Twenty different 
variations were incorporated in a survey that was designed to capture their influence on bid price and overall project duration from four distinct groups' perspectives. Box plots, weighted averages along with the standard deviations, were used to sort the twenty tender law modifications into two perspectives (bid price and overall project duration).

The research analyses have shown that owners confirmed that D3 was the top law modification with regard to bid cost, as it had the highest weighted average of 4.54 among all modifications, and D3, alongside D11, was the top variation with respect to overall project duration. On the other hand, contractors acknowledged D8 and D20 as the top law variations with regard to bid price and overall project duration. The anonymous survey respondent group concluded that D3 and D12 were the two top variations with regard to both attributes. Finally, all participants indicated that D3 and D8 were the top variations with regard to bid price; however, D12 and D11 were the significant law modifications with respect to project duration.

In conclusion, construction participants seeking the involvement in construction bids for projects located in the State of Kuwait or any other countries within the Gulf region have to thoroughly investigate the bidding law, which will greatly influence their bid price, project overall duration, or both. The construction industry as a whole should take into consideration the risks resulting with high influence in bid price and project duration and try to mitigate their impact through laws, legal mature provisions, and contract articles. Owners have to confirm that their contracts are well drafted to overcome and best allocate these modifications. In addition, governments have to investigate and accommodate these modifications in their laws and regulations to mitigate their adverse influence on the construction industry.

\section{ACKNOWLEDGMENT}

The present study was attainable through the Graduate School at Kuwait University. The first author thanks her "CE 541: Engineering and Construction Law" students of fall 2018-2019 for their assistance and support in distributing the survey and gathering the data desired for this research. Likewise, the authors also thank the questionnaire contributors for their valuable input. The data that support the findings of this study are available from the corresponding author, $\mathrm{RS}$, upon reasonable request.

\section{REFERENCES}

Aibinu, A.A., \& Jagboro, G.O. (2002). "The effects of construction delays on project delivery in Nigerian construction industry". International journal of project management, 20(8): 593-599.

Al Fares, J., (2000).“Central tendering: an evaluation of the Kuwait experience”. Loughborough : Jamal Al-Fares, Loughborough University.

Al-Momani, A.H. (2000). Construction delay: a quantitative analysis. International journal of project management, 18(1): 51-59.

Bajaj, D., Oluwoye, J., and Lenard, D. (1997). "An analysis of contractors approaches to risk identification in New South Wales, Australia." Construction Management and Economics.

Chan, D.W., \& Kumaraswamy, M.M. (1997). "A comparative study of causes of time overruns in Hong Kong construction projects". International Journal of project management, 15(1): 55-63.

Cheaitou, A., Larbi, R., and Housani, B.A. (2018). "Decision making framework for tender evaluation and contractor selection in public organizations with risk considerations." Socio-Economic Planning Sciences.

Ciribini, ALC., Bolpagni, M., and Oliveri, E. (2015). “An Innovative Approach to e-public Tendering Based on Model Checking." Procedia Economics and Finance.

Gebken, R.J., \& Gibson, G.E. (2006). Quantification of costs for dispute resolution procedures in the construction industry. Journal of professional issues in engineering education and practice, 132(3): 264-271.

“Global Construction Outlook to 2022: Q3 2018 Update.” (2018). GlobalData, https://www.globaldata.com/store/report/ gdcn0010 go-global-construction-outlook-to-2022-q3-2018update/ (Jul. 7, 2019).

“Kuwait International Airport Passenger Terminal 2.” (2019). Gulf Consult, http://gckuwait.com/portfolio_page/kuwait- 
international-airport-passenger-terminal/ (Jul. 7, 2019).

Laryea, S., and Lubbock, A. (2014). "Tender Pricing Environment of Subcontractors in the United Kingdom." Journal of Construction Engineering and Management.

Mahdi, W., and Al-Amouri, M. (2019). "Kuwait's KNPC awards EPC contracts to construct \$16-billion Al-Zour refinery", https://www.constructionboxscore.com/project-news/kuwait's-knpc-awards-epc-contracts-to-construct-\$16-billion-al-zourrefinery.aspx (Jul. 7, 2019).

Mahmoud, B., (2019). "Sheikh Jaber Al Ahmed Al Sabah Causeway". SSH, https://www.sshic.com/projects/sheikh-jaber-alahmed-al-sabah-causeway (Jul. 7, 2019).

Meacham, B.J. 2010. Accommodating innovation in building regulation: lessons and challenges. Building Research \& Information, 38: 686-698.

Ministry Of Finance, UAE. (2018). https://www.mof.gov.ae/ar/Pages/Default.aspx (Jul.4,2019).

Ministry of Foreign Affairs, KSA. (2017).https://www.mofa.gov.sa/Tenders (Jul.4,2019).

Ojha, A. (2019). “Kuwait construction projects valued at \$494bn in Q2 2019.” Construction Week Online Middle East, Construction Week Online, https://www.constructionweekonline.com/projects-tenders/255680-kuwait-construction-projects-valued-at494bn-in-q2-2019 (Jul. 7, 2019).

Rabia Asif and Sabahat Nisar (2016). "Tender advertisement cost: Significant savings through the use of information and communication technologies (ICT)." 2016 6th International Conference on Information Communication and Management (ICICM).

Raes, F., Pommier, E., Neff, K.D., \& Van Gucht, D. (2011). Construction and factorial validation of a short form of the selfcompassion scale. Clinical psychology \& psychotherapy, 18(3), 250-255.

Sha, K., Yang, J. and Song, R. 2008. Competitiveness assessment system for China's construction industry. Building Research \& Information, 36(1): 97-109.

“The Tendering Law Of The Kingdom of Bahrain.”(2002). http://www.tenderboard.gov (Jul.4,2019).

The European Parliament and the council of the European Union. (2014, March 28). Directive 2014/24/EU of the European Parliament and the Council on Public Procurement. Official Journal of the European Union. 